\section{Gottron Sign with Ulceration Is Not a Poor Prognostic Factor in Patients with Dermatomyositis and Interstitial Lung Disease}

\section{To the Editor:}

We read the recent article by Cao, $e t a l^{1}$ with great interest. They reported that patients with dermatomyositis (DM) who have Gottron papule/sign with ulceration show an increased risk of interstitial lung disease (ILD) and a significantly lower cumulative survival rate. Unlike Cao, et al, we found that the survival of DM patients with ILD and ulcerated Gottron sign was not worse than that of patients without ulceration.

We retrospectively reviewed all the adult patients with DM admitted to our department from 2000 to 2012. The criteria for diagnosis of DM were the same as those used by Cao, et $a l^{1}$. Clinical features and laboratory test results were assessed from the medical records, with laboratory data being those obtained at the first admission. ILD was diagnosed by detection of interstitial changes on chest computed tomography. Cancer-associated myositis was diagnosed if a malignancy was detected within 3 years before or after diagnosis of DM.

Our study was approved by the institutional review board of Jichi Medical University, Shimotsuke, Japan (No. 16-049).

Among 83 patients with DM, 23 (28\%) had widely distributed skin ulcers (on the extensor surfaces of joints, digital pulp/lateral nail folds, axilla, shoulder, auricle, sole, and digital necrosis) at first presentation or during the course of their disease. Of these 23 patients, 15 (65\%) had ulceration of Gottron sign. The median time from admission to the development of ulceration was 3.1 months (range: 0-24 mos). Only 4 of the 15 patients had ulcers on admission, and 2 of these 4 patients had been treated for refractory DM before referral to our hospital. Table 1 compares clinical characteristics between the patients with or without ulceration of Gottron sign. The 2 groups showed differences in the creatine kinase level, white blood cell count, and antinuclear antibody positive rate, as well as the incidence of clinically

Table 1. Comparison of clinical characteristics between patients with or without ulceration of Gottron sign. Values are mean $\pm \mathrm{SD}$ or $\%$.

\begin{tabular}{lccc}
\hline Characteristics & $\begin{array}{c}\text { Patients without } \\
\text { Ulceration, } \mathrm{n}=68\end{array}$ & $\begin{array}{c}\text { Patients with } \\
\text { Ulceration, } \mathrm{n}=15\end{array}$ & $\mathrm{p}$ \\
\hline Age, yrs & $56.3 \pm 15.2$ & $50.9 \pm 13.3$ & 0.21 \\
CADM & 31 & 80 & $0.001^{* *}$ \\
Heliotrope rash & 43 & 67 & 0.09 \\
Fever & 53 & 73 & 0.15 \\
Arthralgia/arthritis & 49 & 73 & 0.08 \\
ILD & 66 & 100 & $0.005^{* *}$ \\
AIP/SIP & 29 & 27 & 0.4 \\
Malignancy & 29 & 0 & $0.016^{*}$ \\
CK, IU/1 & $2424 \pm 4189$ & $156 \pm 162$ & $0.04^{*}$ \\
LDH, IU/1 & $564 \pm 316$ & $462 \pm 252$ & 0.25 \\
AST, IU/1 & $134 \pm 148$ & $99 \pm 69$ & 0.38 \\
WBC, $\times 10^{3} / \mathrm{mm}^{3}$ & $7.8 \pm 3.8$ & $5.2 \pm 1.2$ & $0.009^{* *}$ \\
ESR, mm/h & $41 \pm 28, \mathrm{n}=56^{\dagger}$ & $48 \pm 25, \mathrm{n}=12^{\dagger}$ & 0.4 \\
Serum ferritin, ng/ml & $650 \pm 1056, \mathrm{n}=47^{\dagger}$ & $469 \pm 419, \mathrm{n}=9^{\dagger}$ & 0.95 \\
Anti-Jo1 antibody & 12 & 0 & 0.19 \\
ANA, $\geq 160 \times$ & 43 & 7 & $0.006^{* *}$ \\
Death from AIP/SIP & & & \\
within 1 yr & 9 & 7 & 0.81 \\
\hline
\end{tabular}

$* \mathrm{p}<0.05 . * * \mathrm{p}<0.01 .{ }^{\dagger}$ No. patients in whom ESR or serum ferritin was tested. CADM: clinically amyopathic dermatomyositis; ILD: interstitial lung disease; AIP: acute interstitial pneumonia; SIP: subacute interstitial pneumonia; CK: creatine kinase; LDH: lactate dehydrogenase; AST: aspartate aminotransferase; WBC: white blood cell count; ESR: erythrocyte sedimentation rate; ANA: antinuclear antibody. amyopathic DM, incidence of ILD, and incidence of malignancy. Other clinical and laboratory findings did not differ between the groups. In particular, death from acute/subacute interstitial pneumonia (AIP/SIP) within 1 year showed no difference.

Several reasons can be suggested for the different prognosis of ILD in the patients reported by Cao, et al and our patients. First, their clinical features were quite different. For example, the incidence of fever in patients without ulcers was $3 \%$ and $53 \%$, respectively, while the frequency of AIP/SIP was 3\% and 29\%, respectively. Also, classification of patients by the site of ulceration might have affected mortality, because one-third of our patients had ulcers at sites other than that of Gottron sign and were classified into the ulcer-negative group. However, ulceration of the digital pulp and periungual region is also known to be a feature of patients who are positive for anti-MDA5 antibody ${ }^{2}$, so this might have increased the frequency of AIP/SIP and mortality in the ulcer-negative group ${ }^{3}$.

Second, treatment might have differed between the 2 studies. In other studies, intensive treatment using a combination of prednisolone, calcineurin inhibitors, and cyclophosphamide significantly improved the prognosis of DM patients with $\operatorname{ILD}^{4,5}$. Cao, et al did not describe the treatment of their patients. Our patients with known poor prognostic factors (e.g., high serum ferritin) received intensive immunosuppressive therapy, which may have led to a higher survival rate ${ }^{6}$.

Third, patients with rapidly progressive AIP might die before the development of ulcers. In our patient population, the median time from admission to detection of ulcers was 3.1 months (range: 0-24 mos). Only 4 of the 15 patients had ulcers on admission and 2 of them were referred to us with refractory DM. Among 68 patients without ulcers, $6(9 \%)$ died of AIP and all of them died within 2 months after admission. The clinical course of these patients might have been too short for the development of ulcers.

It has not yet been determined whether DM patients with ILD and ulcerated Gottron sign have a worse prognosis. The sites of ulceration were not mentioned in most previous reports, but some showed a worse prognosis of ILD associated with ulcers ${ }^{7,8}$ and others did not ${ }^{9,10}$. A Japanese multicenter study found no difference in the incidence of skin ulcers between patients positive for anti-MDA5 antibody who died and those who survived $^{9}$.

Ulceration of Gottron sign was not an adverse prognostic factor for ILD in our patients. Our findings suggest that a certain population of patients with skin ulcers may have chronic ILD.

TAKAO NAGASHIMA, MD, PhD, Division of Rheumatology and Clinical Immunology, Department of Medicine, Jichi Medical University; MASAHIRO IWAMOTO, MD, PhD, Division of Rheumatology and Clinical Immunology, Department of Medicine, Jichi Medical University; SEIJI MINOTA, MD, PhD, Division of Rheumatology and Clinical Immunology, Department of Medicine, Jichi Medical University, Shimotsuke, Japan. Address correspondence to Dr. T. Nagashima, Division of Rheumatology and Clinical Immunology, Department of Medicine, Jichi Medical University, Yakushiji 3311-1, Shimotsuke, Tochigi 329-0498, Japan. E-mail: naga4ma@jichi.ac.jp

\section{REFERENCES}

1. Cao H, Xia Q, Pan M, Zhao X, Li X, Shi R, et al. Gottron papules and Gottron sign with ulceration: a distinctive cutaneous feature in a subset of patients with classic dermatomyositis and clinically amyopathic dermatomyositis. J Rheumatol 2016;43:1735-42.

2. Narang NS, Casciola-Rosen L, Li S, Chung L, Fiorentino DF. Cutaneous ulceration in dermatomyositis: association with anti-melanoma differentiation-associated gene 5 antibodies and interstitial lung disease. Arthritis Care Res 2015;67:667-72.

3. Moghadam-Kia S, Oddis CV, Sato S, Kuwana M, Aggarwal R. Anti-melanoma differentiation-associated gene 5 is associated with rapidly progressive lung disease and poor survival in US patients with amyopathic and myopathic dermatomyositis. Arthritis Care Res 2016;68:689-94. 
4. Kurita T, Yasuda S, Oba K, Odani T, Kono M, Otomo K, et al. The efficacy of tacrolimus in patients with interstitial lung diseases complicated with polymyositis or dermatomyositis. Rheumatology 2015;54:39-44.

5. Kotani T, Makino S, Takeuchi T, Kagitani M, Shoda T, Hata A, et al. Early intervention with corticosteroids and cyclosporin A and 2-hour postdose blood concentration monitoring improves the prognosis of acute/subacute interstitial pneumonia in dermatomyositis. J Rheumatol 2008;35:254-9.

6. Nagashima T, Minota S. Comment on: The efficacy of tacrolimus in patients with interstitial lung diseases complicated with polymyositis or dermatomyositis. Rheumatology 2015;54:1128-9.

7. Ishigaki K, Maruyama J, Hagino N, Murota A, Takizawa Y, Nakashima R, et al. Skin ulcer is a predictive and prognostic factor of acute or subacute interstitial lung disease in dermatomyositis.
Rheumatol Int 2013;33:2381-9.

8. Mimori A, Suzuki T, Satoh N, Nara H, Masuyama J, Yoshio T, et al. Dermatomyositis and cutaneous necrosis: report of five cases. Mod Rheumatol 2000;10:117-20.

9. Hamaguchi Y, Kuwana M, Hoshino K, Hasegawa M, Kaji K, Matsushita T, et al. Clinical correlations with dermatomyositis-specific autoantibodies in adult Japanese patients with dermatomyositis: a multicenter cross-sectional study. Arch Dermatol 2011;147:391-8.

10. Hall JC, Casciola-Rosen L, Samedy LA, Werner J, Owoyemi K, Danoff SK, et al. Anti-melanoma differentiation-associated protein 5-associated dermatomyositis: expanding the clinical spectrum. Arthritis Care Res 2013;65:1307-15.

J Rheumatol 2017;44:7; doi:10.3899/jrheum.170068 